\title{
Amniotic fluid embolism as a cause of maternal mortality in China between 1996 and 2013: a population-based retrospective study
}

$\mathrm{Yi} \mathrm{Mu}^{1 \dagger}$, Nolan McDonnell ${ }^{2,4+}$, Zhuoyang $\mathrm{Li}^{3}$, Juan Liang ${ }^{1}$, Yanping Wang ${ }^{1}$, Jun Zhu ${ }^{{ }^{*}}$ and Elizabeth Sullivan ${ }^{3^{*}}$

\begin{abstract}
Background: To analyse the maternal mortality ratio, demographic and pregnancy related details in women who suffered a fatal amniotic fluid embolism (AFE) in China.

Methods: A retrospective population based study using data collected as part of the National Maternal Mortality Surveillance System between 1996 and 2013. Data were collected onto a standardised form from women whose cause of death was listed as being secondary to AFE.

Results: Records were available for 640 deaths. Over the 17 year period the maternal mortality ratio for AFE decreased from 4.4 per 100,000 births (95\% confidence interval (Cl):2.72-6.12) to 1.9 per 100,000 births (95\% Cl:1. 35-2.54). Over the same period the proportion of maternal deaths secondary to AFE increased from 6.8 to $12.5 \%$. The mean age of women who died was 30.1 years and the onset of the AFE occurred prior to delivery in $39 \%$. The most prominent presenting features included premonitory symptoms (29\%), acute fetal compromise (28\%), maternal haemorrhage (16\%) and shortness of breath (15\%).

Conclusions: Maternal mortality secondary to AFE has decreased in China, however at a slower rate than mortality secondary to other conditions. Active surveillance is recommended to assess case fatality rates, risk factors and other lessons specific to this population.
\end{abstract}

Keywords: Amniotic fluid embolism, Maternal mortality ratio, Maternal mortality, Maternal death, Pregnancy, China

\section{Background}

In September 2000 the United Nations Millennium Declaration committed world leaders to improving the health and wellbeing of member states by the year 2015 through a number of specific Development Goals [1]. Millennium Development Goal 5 (MDG5) aims to improve maternal health and more specifically, Target 5.A. aims to reduce the maternal mortality ratio (MMR) by

\footnotetext{
*Correspondence: zhujun028@163.com; elizabeth.sullivan@uts.edu.au ${ }^{\dagger}$ Equal contributors

${ }^{1}$ National Office for Maternal and Child Health Surveillance of China, Department of Obstetrics, West China Second University Hospital, Key Laboratory of Birth Defects and Related Diseases of Women and Children, Ministry of Education, Sichuan University, Ren Min South Road Section 3 No.17, Chengdu, Sichuan, China

${ }^{3}$ Faculty of Health, University of Technology Sydney, 235 Jones St, Ultimo, Sydney, NSW 2007, Australia

Full list of author information is available at the end of the article
}

three quarters for the time period 1990-2015 [2]. Currently, approximately 290,000 women die each year from pregnancy related complications [3]. Throughout the world there are significant differences in the MMR secondary to a number of factors including the underlying socioeconomic state of the population, geographical location, access to contraception and access to skilled birth attendants [3-5].

China has had well documented success in reducing their maternal mortality in line with MDG5 [6]. This has been in large part secondary to the transition to women giving birth in a hospital environment [7]. This has been supported by widespread media campaigns, subsidies to promote hospital based birth, infrastructure improvements as well as increased training for staff involved in the care of pregnant women $[8,9]$. The majority of the decrease in maternal 
mortality can be explained by a reduction in more potentially preventable causes of mortality such as haemorrhage, hypertensive disorders of pregnancy and sepsis [10].

Amniotic fluid embolism (AFE) is a rare complication of pregnancy with a comparatively high mortality [11]. It often presents as the sudden onset of cardiovascular collapse, respiratory compromise and disseminated intravascular coagulation. AFE is a poorly understood condition whose management requires prompt and timely access to providers with training in maternal resuscitation as well as resources to manage the potential cardiovascular, respiratory and haematological compromise [11]. In contrast to developing nations, in wellresourced countries such as Australia, New Zealand and the United Kingdom AFE is a leading cause of maternal mortality [12-14]. However, there has been little attention focused on AFE as a contributor to maternal mortality in developing nations.

As countries continue to work towards reducing their maternal mortality, conditions such as AFE are likely to become more prominent as other more preventable causes decline in frequency. The aim of this present study was to analyse the MMR, demographic and pregnancy related details in women who suffered a fatal AFE in China between January 11996 and September 302013.

\section{Methods}

This study was designed as a population based study using data collected as part of the National Maternal Mortality Surveillance System (NMMSS). The NMMSS is part of the National Maternal and Child Health Surveillance System (MCHSS) and was established by the Chinese Ministry of Health in 1989. The process of the establishment of the NMMSS and the methods of data collection have been described in detail elsewhere [10]. From 1996 to 2006, the MCHSS covered 176 surveillance districts/counties representing approximately 80 million people with an annual number of live births ranged from 493,662 to 622,856 . After 2006, the MCHSS was expended to 336 surveillance districts/counties covering approximately 140 million people with an annual number of live births ranged from $1,759,539$ to 2,111,365.

For the purposes of the NMMSS a maternal death is classified in line with the World Health Organization (WHO) definition [15] and is the death of a woman while pregnant or within 42 days of termination of pregnancy, irrespective of the duration and of the pregnancy, from any cause related to or aggravated by pregnancy or its management, but not from accidental or incidental causes.

A standardised procedure is used to determine the cause of death for each case that each maternal death is reviewed by four levels of committees (county/district review committee, municipal review committee, provincial review committee and the National Review Committee) [16]. If a maternal death occurs, the death is investigated by trained obstetricians including interviews of the family, midwives, physicians and nursing staffs. The information were collected using a standardised form on prenatal care; history of the pregnancy; course of delivery; the date of delivery and death; cause of maternal death and details of the treatment provided. This information is then reviewed by a county/district review committee to determine the cause of death and identify factors contributing to death. A maternal death secondary to AFE is defined either as a clinical diagnosis (acute hypotension or cardiac arrest, acute hypoxia, acute pulmonary embolism, cardiovascular collapse, disseminated intravascular coagulation, renal failure and a series of pathological changes in the absence of any other potential explanation for the symptoms and signs observed) or as a post mortem diagnosis (presence of fetal debris in the circulation). The municipal and provincial maternal and child health institutions review and verify the investigative reports. Finally, committees at the provincial and national level re-examine the results submitted by the subordinate committee and make the final decision as to the likely cause of death. The ascertainment rate of maternal death was approximately $96 \%$ for all causes of death.

For the purposes of this study the NMMSS database was examined for maternal deaths between January 1 1996 and September 302013 where AFE was recorded as the cause of death. Data was then extracted from the mortality records using a standardised data collection form based on those originally developed by the Australasian Maternity Outcomes Surveillance System (AMOSS) [17], and then modified by the National Office for Maternal and Child Health Surveillance. The modified survey form included baseline demographic and pregnancy factors, obstetric interventions, the location of the woman's initial presentation/collapse, the most prominent initial presenting feature, other associated features, therapy required, results of relevant investigations and maternal and perinatal outcomes. Premonitory symptoms are defined as those present before the abrupt change in maternal condition that led to the diagnosis of AFE and may include: breathlessness, chest pain, feeling cold, light headedness, restlessness, distress, panic, a feeling of pins and needles in the fingers, nausea and vomiting. A stillbirth was defined in accordance with WHO criteria, that being a baby born with no signs of life after 28 weeks gestation. A neonatal death was defined as death occurring within the first 28 days post-delivery. 


\section{Statistical methods}

The MMR was calculated from the number of maternal deaths per 100000 live births. The $95 \%$ confidence intervals (CI) of the MMR in urban and rural areas were calculated by assuming that the counts follow a Poisson distribution. We did statistical analyses with SPSS software (version 16.0; SPSS Inc., Chicago, IL, USA).

\section{Results}

Over the course of the study period there were 664 recorded deaths secondary to AFE, of which summary medical records were available for 640 cases. Over the corresponding period there were 20,006,880 live births, giving an estimated maternal mortality from AFE of 1:30,131 births (95 \% CI: 1:26001-1: 32611 births). The
MMR for AFE over the study period decreased from 4.4 per 100,000 (95\% CI 2.72-6.12) in 1996 to 1.9 per 100,000 (95 \% CI 1.35-2.54) in 2013 (Fig. 1a). Over the corresponding period the proportion of maternal deaths secondary to AFE increased from $6.8 \%$ in 1996 to $12.5 \%$ in 2013 (Fig. 2).

The demographic details of the women who died are shown in Table 1 . The mean age of the women who died was $30.1( \pm 5.4)$ years. Eighty four percent of pregnancies were singleton. The onset of the AFE episode occurred prior to delivery in $39 \%$ and after delivery in $53 \%$ (unknown in $8 \%$ ) (Table 2). For those cases that occurred postpartum, $78 \%$ occurred in the first $60 \mathrm{~min}$ after delivery (56\% in the first 30 mins, $22 \%$ between 30-60 min after delivery). The location of the AFE episode was
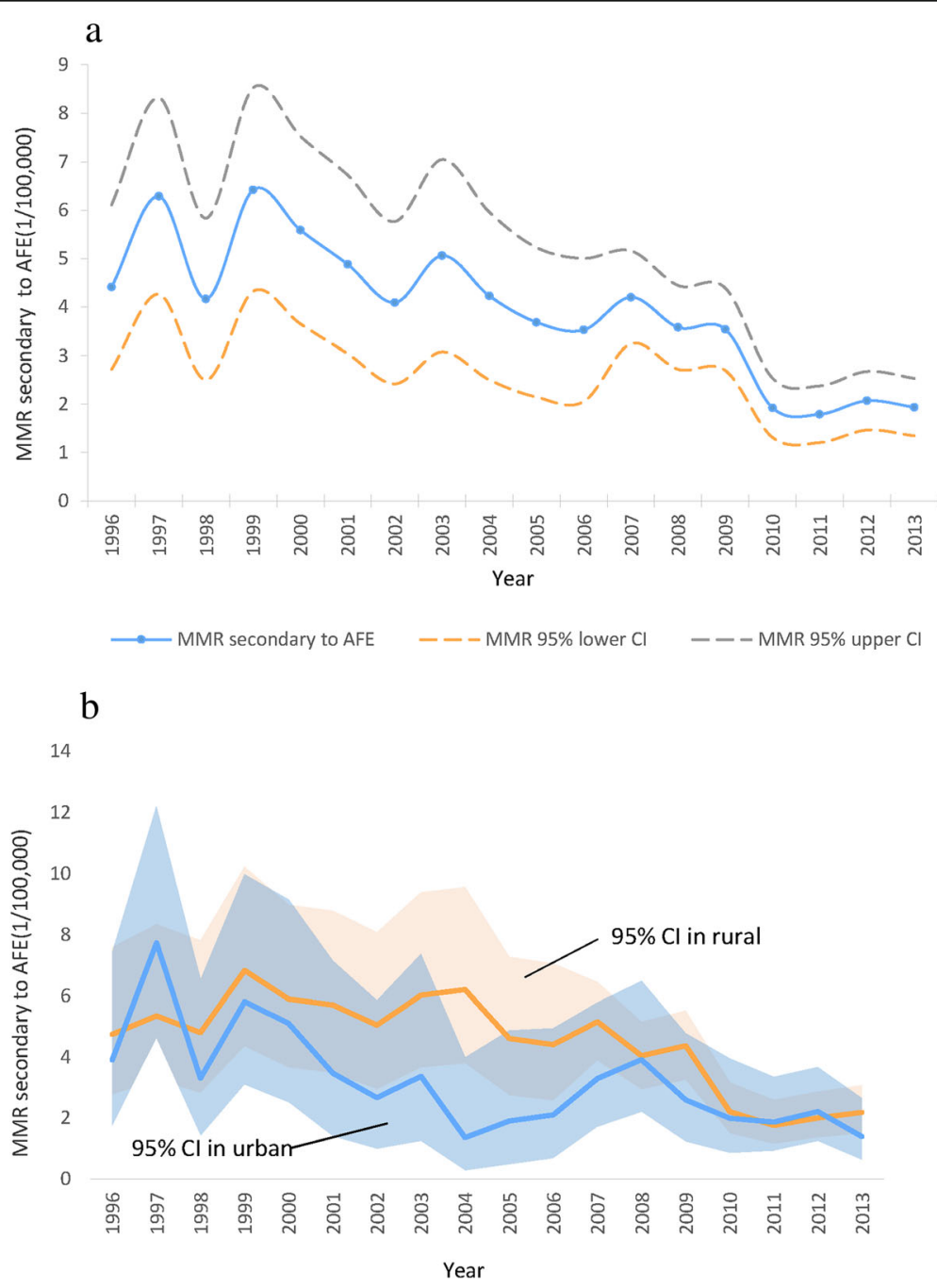

Fig. 1 a Maternal mortality secondary to amniotic fluid embolism in China, 1996-2013. b Maternal mortality secondary to amniotic fluid embolism in urban and rural China, 1996-2013 


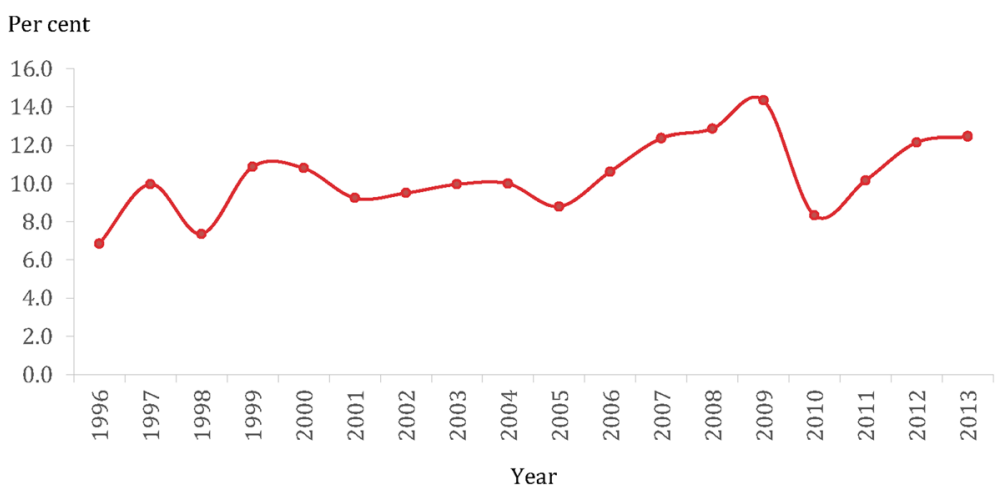

Fig. 2 The proportion of of maternal deaths secondary to amniotic fluid embolism in China, 1996-2013

Table 1 Demographic and obstetric characteristics of the maternal deaths secondary to amniotic fluid embolism in China, 1996-2013

\begin{tabular}{|c|c|c|}
\hline Demographic and obstetric characteristics & Number & Percent \\
\hline Age (year) Mean (SD) & $30.1(5.4)$ & \\
\hline \multicolumn{3}{|l|}{ Age (year) } \\
\hline$<25$ & 85 & 13.3 \\
\hline $25-29$ & 158 & 24.7 \\
\hline $30-34$ & 227 & 35.5 \\
\hline$>=35$ & 170 & 26.5 \\
\hline \multicolumn{3}{|l|}{ Ethnicity } \\
\hline Han & 557 & 87.0 \\
\hline Other & 83 & 13.0 \\
\hline \multicolumn{3}{|l|}{ Education } \\
\hline Literate & 35 & 5.5 \\
\hline Primary & 169 & 26.4 \\
\hline High & 396 & 61.9 \\
\hline Collage or above & 35 & 5.5 \\
\hline Unknown & 5 & 0.8 \\
\hline \multicolumn{3}{|l|}{ Parity } \\
\hline Primiparas & 309 & 48.3 \\
\hline Multiparas & 329 & 51.4 \\
\hline Unknown & 2 & 0.3 \\
\hline \multicolumn{3}{|l|}{ Number of gestations } \\
\hline Singleton & 539 & 84.2 \\
\hline Twins & 14 & 2.2 \\
\hline Three or more & 12 & 1.9 \\
\hline Unknown & 75 & 11.7 \\
\hline \multicolumn{3}{|l|}{ Number of antenatal visits } \\
\hline 0 & 53 & 8.3 \\
\hline 1 & 36 & 5.6 \\
\hline $2-4$ & 218 & 34.1 \\
\hline$>=5$ & 305 & 47.7 \\
\hline Unknown & 28 & 4.4 \\
\hline
\end{tabular}

recorded as being at home in $8.4 \%$ of cases, in the delivery suite in $36 \%$ of cases, the operating theatre in $13 \%$ and the maternity ward in $14 \%$. Twenty four percent of women did not give birth whilst $60 \%$ had a vaginal birth and $16 \%$ a caesarean delivery.

The most prominent initial presenting feature and the associated presenting features varied by the pregnancy state at the onset of the collapse (Figs. 3 and 4). Overall, premonitory symptoms were the most commonly described initial presenting feature $(29 \%)$ followed by acute fetal compromise (28\%), maternal haemorrhage (16\%) and shortness of breath (15\%).

Details of the treatment required are shown in Table 3. Cardiopulmonary resuscitation was performed in $75 \%$ of women whilst $40 \%$ required intubation and ventilation. Thirty seven percent of women were administered blood or blood products and a hysterectomy was performed in $18 \%$. The time from the onset of the AFE episode until death was confirmed is shown in Fig. 5. An autopsy was performed in 43 women $(6.7 \%)$ and in 10 $(23.3 \%)$ there was documented evidence of material consistent with amniotic fluid in the maternal pulmonary circulation.

Only limited neonatal data were able to be extracted from the NMMSS. Twenty four percent of women did not give birth (died undelivered), for the remaining $76 \%$ of women $(n=486)$ information was only available for 160 of which there were 91 stillbirths, 30 neonatal deaths and 39 neonates surviving past 27 days of age.

\section{Discussion}

Between 1996 and 2013 there were 664 deaths classified as being secondary to AFE in the regions of China that participated in the NMMSS maternal mortality surveillance. Over this time period the MMR secondary to AFE declined from 4.4 to 1.9 per 100,000 births however the proportion of maternal 
Table 2 Delivery and collapse details of the maternal deaths secondary to amniotic fluid embolism in China, 1996-2013

\begin{tabular}{|c|c|c|}
\hline Delivery and collapse details & Number & Percent \\
\hline \multicolumn{3}{|c|}{ Rupture of membranes prior to onset } \\
\hline Yes & 504 & 78.8 \\
\hline Artificial & 100 & 15.6 \\
\hline Spontaneously & 315 & 49.2 \\
\hline Unknown & 89 & 13.9 \\
\hline No & 136 & 21.3 \\
\hline \multicolumn{3}{|l|}{ Meconium stained liquor } \\
\hline None & 79 & 12.3 \\
\hline Fresh & 60 & 9.4 \\
\hline Old & 101 & 15.8 \\
\hline Unknown & 400 & 62.5 \\
\hline \multicolumn{3}{|l|}{ Method of birth } \\
\hline Undelivered $^{a}$ & 154 & 24.1 \\
\hline Non-instrumental vaginal & 290 & 45.3 \\
\hline Instrumental vaginal & 93 & 14.5 \\
\hline Caesarean & 103 & 16.1 \\
\hline \multicolumn{3}{|l|}{ Location of onset of symptoms } \\
\hline Home & 54 & 8.4 \\
\hline Maternity ward & 91 & 14.2 \\
\hline Labour room & 6 & 0.9 \\
\hline Theatre & 85 & 13.3 \\
\hline Delivery Suite & 227 & 35.5 \\
\hline Other & 28 & 4.4 \\
\hline Unknown & 149 & 23.3 \\
\hline \multicolumn{3}{|c|}{ Pregnancy state at onset of collapse } \\
\hline Pre-labour & 30 & 4.7 \\
\hline First stage & 112 & 17.5 \\
\hline Second stage & 111 & 17.3 \\
\hline Post delivery & 337 & 52.7 \\
\hline Unknown & 50 & 7.8 \\
\hline \multicolumn{3}{|c|}{ Time from delivery until onset of symptoms ${ }^{b}$} \\
\hline $0 \sim 0.5 \mathrm{~h}$ after delivery & 141 & 55.73 \\
\hline $0.5 \sim 1 \mathrm{~h}$ after delivery & 55 & 21.74 \\
\hline $1 \sim 1.5 \mathrm{~h}$ after delivery & 23 & 9.09 \\
\hline $1.5 \sim 2 \mathrm{~h}$ after delivery & 8 & 3.16 \\
\hline $2 \sim$ hours after delivery & 26 & 10.28 \\
\hline \multicolumn{3}{|l|}{ Place of death } \\
\hline Hospital & 554 & 86.6 \\
\hline City & 169 & 26.4 \\
\hline County & 261 & 40.8 \\
\hline Township & 121 & 18.9 \\
\hline Village & 3 & 0.5 \\
\hline
\end{tabular}

Table 2 Delivery and collapse details of the maternal deaths secondary to amniotic fluid embolism in China, 1996-2013 (Continued)

\begin{tabular}{lll}
\hline Home & 39 & 6.1 \\
On the way to hospital & 42 & 6.6 \\
Other & 5 & 0.8 \\
\hline
\end{tabular}

Including termination of pregnancy

${ }^{\mathrm{b}}$ If delivered prior to onset of symptoms

deaths secondary to AFE increased from $6.8 \%$ in 1996 to $12.5 \%$ in 2013. Although the proportion of maternal deaths secondary to AFE has increased over this period, the absolute numbers have decreased most likely reflecting the more rapid decline in deaths secondary to more preventable and common causes such as haemorrhage.

The major strength of this study is the large number of maternal deaths secondary to AFE. The 664 deaths reported here represent internationally the largest cohort of maternal deaths to have been reported. As the data was collected over a 17 year time period and across a broad geographical area, it provides contemporary information on the trends in MMR from AFE over this time period and also the differences across urban versus rural China. However, as data for these cases was collected retrospectively from a standardised dataset, only limited data that was routinely entered as part of the NMMSS data collection process was available for review. Population based data collection without the use of additional criteria to exclude false positive cases may lead to an overestimation of the true incidence [18]. As there is currently no active surveillance of AFE in China it is not possible to report a case fatality rate, overall incidence of AFE as well as risk factors for AFE and factors associated with survival from AFE. Data in relation to fetal outcomes was limited by a lack of routine neonatal data collection in the NMMSS. As AFE is a diagnosis of exclusion [19], maternal autopsy is important to help exclude other potential causes of collapse and it has been a consistent message from the UK Confidential Enquiries that access to high quality pathology services is required for maternal deaths $[14,20]$ and guidelines for the performance of a maternal autopsy are available [21]. Of the 664 deaths reported here, only $43(6.5 \%)$ women underwent a post mortem examination, potentially secondary to a historical lack of access to pathology services. This low rate of post mortem examination may lead to higher numbers of both false positive and false negative diagnoses and suggest that efforts to further improve the maternal mortality in China should also be done in conjunction 


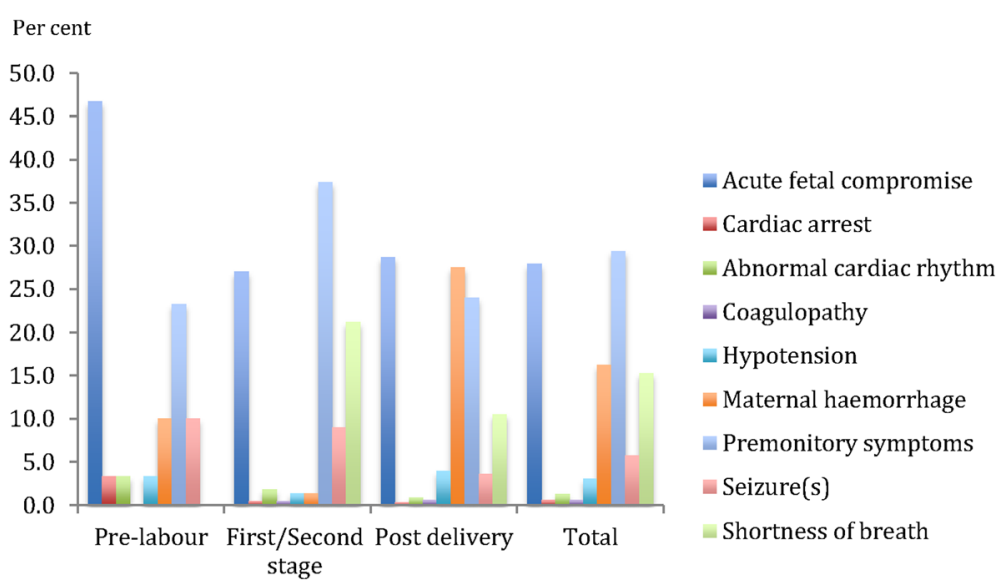

Fig. 3 The single most prominent initial presenting feature by pregnancy state at onset of collapse of maternal deaths secondary to amniotic fluid embolism in China, 1996-2013

with efforts to increase the access to and uptake of maternal autopsy.

The decrease in the MMR from AFE in this population is likely to be secondary to the considerable efforts focused on improving maternal mortality in China since the establishment of the Millennium Development Goals. In line with MDG5, the Chinese government invested considerable resources in decreasing maternal mortality. Projects such as the "Reducing Maternal Mortality and Eliminating Newborn Tetanus" have aimed to promote hospital based births for rural women as well as improve resources and training of staff [22]. However, despite the decrease, the MMR reported here is similar to other developing countries (ranged between 1.8-5.9 per 100,000 deliveries) [23] and higher than in many developed countries. The most recent triennial confidential enquiry into maternal deaths in the UK and Ireland reports an MMR from AFE of 0.33 per 100,000 [14] whilst data from Australia reports an MMR of 0.6 per 100,000 [12]. A number of factors may explain these differences, including socio-economic factors as well as timely access to skilled health care providers in the event of maternal compromise. Previously, the MMR in rural versus urban areas in China has shown significant disparity [10] with a larger number of more preventable deaths [16]. This gap between rural and urban areas now appears to be narrowing [24] and in the data presented here, the MMR for AFE is now similar for both rural and urban areas.

In this study, the most prominent initial presenting feature differed depending on the pregnancy state of the

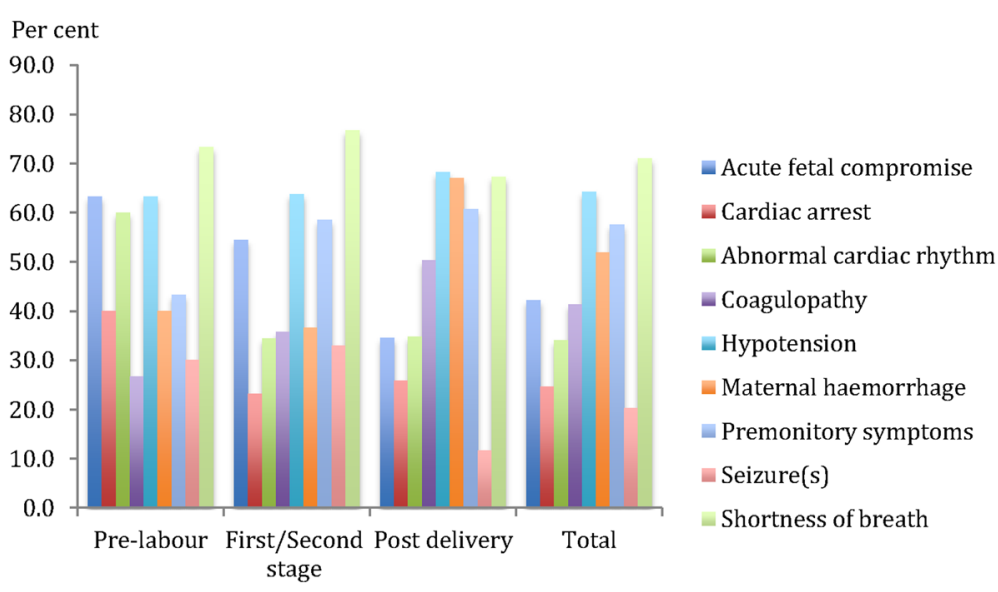

Fig. 4 Overall presenting features by pregnancy state at onset of collapse of maternal deaths to amniotic fluid embolism in China, 1996-2013 
Table 3 Treatment required during the management of the maternal deaths secondary to Amniotic fluid embolism in China, 1996-2013

\begin{tabular}{llc}
\hline Treatment & Number & Percent \\
\hline Cardiopulmonary resuscitation & 478 & 74.7 \\
Intubation/Ventilation & 258 & 40.3 \\
Hysterectomy & 113 & 17.7 \\
Recombinant Factor VIla & 32 & 5.0 \\
Blood and blood products & 239 & 37.3 \\
\hline
\end{tabular}

mother. Previous studies have generally not differentiated the presenting features in relation to the pregnancy state and in this regard the data presented here provides useful information that may assist with more timely recognition of an AFE episode. Women whose onset of the AFE occurred in utero showed a high incidence of acute fetal compromise as the initial presenting feature, most likely because the uteroplacental unit is often very sensitive to changes in the maternal haemodynamic state. The development of acute fetal compromise, especially in the presence of abnormal maternal signs and symptoms, should alert the care provider of the potential for impending maternal deterioration and potentially prompt the mobilisation of additional resources.

Currently in China there is no widespread system in place to monitor rare conditions of pregnancy. Obstetric surveillance systems such the AMOSS and the UK Obstetric Surveillance System (UKOSS) have demonstrated the benefit that these systems can have in furthering the understanding of rare conditions of pregnancy [25] as well as in rapidly responding to emerging issues that can impact on pregnant women [26]. In relation to AFE, the lack of an active surveillance system means potentially important clinical and health systems information specific to the Chinese population and maternity care context regarding risk factors for AFE, comparisons of women who survive and don't survive their AFE as well as overall case fatality rates are not able to be reported. Given the comparatively high MMR for AFE reported here, the establishment of a surveillance system for AFE and other rare conditions of pregnancy is likely to be a worthwhile investment, not only in China, but also in other developing nations who have undergone significant reductions in maternal mortality.

\section{Conclusions}

The MMR secondary to AFE in a large Chinese population declined by over $50 \%$ in the 17 year period from 1996-2013. Over this same time period and as a likely consequence of a reduction in deaths from more preventable causes, the proportion of maternal deaths secondary to AFE increased. The likely reasons for the decline in the mortality ratio from AFE include the greater urbanisation of the Chinese population in conjunction with improved health care in more disadvantaged regions. As other developing nations are likely to go through similar changes in the risk profile of maternal deaths, there are a number of potential lessons to be learned. To more comprehensively study rare disorders of pregnancy, the use of surveillance systems similar to that used in Australia/New Zealand (AMOSS) and the UK (UKOSS) potentially provide more useful information then that derived from conventional mortality reporting. As AFE may present suddenly and require prompt and significant multi-disciplinary resources to effectively manage, the provision of appropriate training and infrastructure in delivery settings is important to improve outcomes and may require significant investment in more isolated regions.

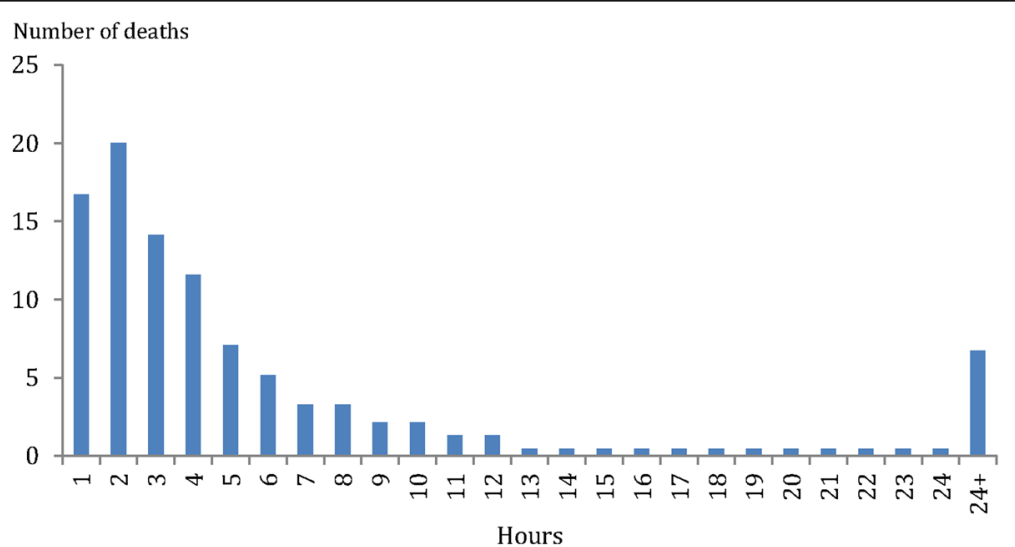

Fig. 5 Time from the onset of the amniotic fluid embolism episode until death, maternal deaths secondary to amniotic fluid embolism in China, 1996-2013 


\section{Abbreviations}

AFE: Amniotic fluid embolism; MDG5: Millennium development goal 5; MMR: Maternal mortality ratio; NMMSS: National Maternal Mortality Surveillance System; MCHSS: National Maternal and Child Health Surveillance System; WHO: World Health Organization; AMOSS: Australasian Maternity Outcomes Surveillance System; Cl: Confidence intervals; UK: the United Kingdom of Great Britain and Northern Ireland; UKOSS: UK Obstetric Surveillance System

\section{Acknowledgments}

The National Health and Family Planning Commission of the People's Republic of China is the funding body of the NMMSS. The authors acknowledge the health workers in this surveillance system for providing the data and investigating the causes of death.

\section{Funding}

Not applicable.

\section{Availability of data and materials}

Data will not be shared because using these data need the permission from the National Health and Family Planning Commission of China.

\section{Authors' contributions}

All authors have contributed to the conducting of this study. YM participated in the study design, acquisition, analysis, and interpretation of data and assisted in drafting the manuscript. NM participated in the study design, interpretation of data and drafting the manuscript. ZL participated in the study design, interpretation of data and assisted in drafting the manuscript. JL, YW, JZ and ES have participated in the study design and revised the manuscript critically for important intellectual content. All authors have read, and confirm that they meet, ICMJE criteria for authorship. All authors read and approved the final manuscript.

\section{Competing interests}

The authors declare that they have no competing interests.

\section{Consent for publication}

Not applicable.

\section{Ethics approval and consent to participate}

Ethical approval for the NMMSS is provided by the Ethics Committee of West China Second University Hospital, Sichuan University, China.

\section{Author details}

${ }^{1}$ National Office for Maternal and Child Health Surveillance of China, Department of Obstetrics, West China Second University Hospital, Key Laboratory of Birth Defects and Related Diseases of Women and Children, Ministry of Education, Sichuan University, Ren Min South Road Section 3 No.17, Chengdu, Sichuan, China. 'School of Women's and Infants' Health and School of Medicine and Pharmacology, University of Western Australia, Perth, Australia. ${ }^{3}$ Faculty of Health, University of Technology Sydney, 235 Jones St, Ultimo, Sydney, NSW 2007, Australia. ${ }^{4}$ Department of Anaesthesia and Pain Medicine, King Edward Memorial Hospital for Women, 374 Bagot Road, Subiaco, WA 6008, Australia.

\section{Received: 31 May 2016 Accepted: 11 October 2016}

\section{Published online: 19 October 2016}

\section{References}

1. United Nations General. United Nations Millennium Declaration. A/RES/55/2 New York: United Nations; 2000.

2. United Nations Secretary-General. Road map towards the implementation of the United Nations Millennium Declaration: Report of the SecretaryGeneral 2001. New York: United Nations; 2001

3. Say L, Chou D, Gemmill A, Tuncalp O, Moller AB, Daniels J, et al. Global causes of maternal death: a WHO systematic analysis. Lancet Global Health. 2014:2(6):e323-33.

4. Feng XL, Zhu J, Zhang L, Song L, Hipgrave D, Guo S, et al. Socio-economic disparities in maternal mortality in China between 1996 and 2006. BJOG. 2010;117(12):1527-36.
5. Kassebaum NJ, Bertozzi-Villa A, Coggeshall MS, Shackelford KA, Steiner C, Heuton KR, et al. Global, regional, and national levels and causes of maternal mortality during 1990-2013: a systematic analysis for the Global Burden of Disease Study 2013. Lancet. 2014:384(9947):980-1004.

6. Kuruvilla S, Schweitzer J, Bishai D, Chowdhury S, Caramani D, Frost L, et al. Success factors for reducing maternal and child mortality. Bull World Health Organ. 2014;92(7):533-44B

7. Gyaltsen Gongque Jianzan K, Gyal Li Xianjia L, Gipson JD, Kyi Cai Rangji T, Pebley AR. Reducing high maternal mortality rates in western China: a nove approach. Reprod Health Matters. 2014;22(44):164-73.

8. Feng XL, Guo S, Hipgrave D, Zhu J, Zhang L, Song L, et al. China's facilitybased birth strategy and neonatal mortality: a population-based epidemiological study. Lancet. 2011;378(9801):1493-500.

9. Liu X, Yan H, Wang D. The evaluation of "Safe Motherhood" program on maternal care utilization in rural western China: a difference in difference approach. BMC Public Health. 2010;10:566.

10. Liang J, Zhu J, Dai L, Li X, Li M, Wang Y. Maternal mortality in China, 1996-2005. Int J Gynaecol Obstet. 2010;110(2):93-6.

11. McDonnell NJ, Percival V, Paech MJ. Amniotic fluid embolism: a leading cause of maternal death yet still a medical conundrum. Int J Obstet Anesth. 2013;22(4):329-36

12. Johnson S, Bonello MR, Li Z, Hilder L, Sullivan EA. Maternal deaths in Australia 2006-2010, Maternal deaths series no.4, Cat. no. PER 61. Canberra: AlHW; 2014.

13. PMMRC. Seventh Annual Report of the Perinatal and Maternal Mortality Review Committee. Reporting mortality 2011. Wellington: Health Quality \& Safety Commission; 2013.

14. Knight M, Kenyon S, Brocklehurst P, Neilson J, Shakespeare J, Kurinczuk JJ, on behalf of MBRRACE- UK. Saving lives, improving Mothers' care - lessons learned to inform future maternity care from the UK and Ireland confidential enquiries into maternal deaths and morbidity 2009-12. Oxford: National Perinatal Epidemiology Unit, University of Oxford; 2014.

15. World Health Organization. International Statistical Classification of Diseases and Related Health Problems (ICD-10). 10th rev, Geneva: WHO; 1993.

16. Liang J, Dai L, Zhu J, Li X, Zeng W, Wang H, et al. Preventable maternal mortality: geographic/rural-urban differences and associated factors from the population-based Maternal Mortality Surveillance System in China. BMC Public Health. 2011:11:243.

17. McDonnell N, Knight M, Peek MJ, Ellwood D, Homer CS, McLintock C, et al. Amniotic fluid embolism: an Australian-New Zealand population-based study. BMC Pregnancy Childbirth. 2015;15(1):352.

18. Knight M, Berg C, Brocklehurst P, Kramer M, Lewis G, Oats J, et al. Amniotic fluid embolism incidence, risk factors and outcomes: a review and recommendations. BMC Pregnancy Childbirth. 2012;12:7.

19. Clark SL. Amniotic fluid embolism. Obstet Gynecol. 2014;123(2 Pt 1):337-48.

20. Cantwell R, Clutton-Brock T, Cooper G, Dawson A, Drife J, Garrod D, et al. Saving Mothers' Lives: Reviewing maternal deaths to make motherhood safer: 2006-2008. The Eighth Report of the Confidential Enquiries into Maternal Deaths in the United Kingdom. BJOG. 2011;118 Suppl 1:1-203.

21. Royal College of Pathologists. Guidelines on Autopsy Practice. Scenario 5: Maternal Death. London: Royal College of Pathologists; 2010.

22. Li X, Zhu J, Dai L, Li M, Miao L, Liang J, et al. Trends in maternal mortality due to obstetric hemorrhage in urban and rural China, 1996-2005. J Perinat Med. 2011;39(1):35-41.

23. Conde-Agudelo A, Romero R. Amniotic fluid embolism: an evidence-based review. Am J Obstet Gynecol. 2009:201(5):445.e1-13.

24. You H, Bogg L, De Costa A, Dong H. Rural maternal mortality ratio in China. Lancet Global Health. 2014;2(8):e451-2.

25. Knight M, Lindquist A. The UK Obstetric Surveillance System: impact on patient safety. Best Pract Res Clin Obstet Gynaecol. 2013;27(4):621-30.

26. ANZIC. Influenza Investigators, Australasian Maternity Outcomes Surveillance System. Critical illness due to 2009 A/H1N1 influenza in pregnant and postpartum women: population based cohort study. BMJ. 2010;340:C1279. 